\title{
RELATION OF DIFFERENT STRAINS OF INFLUENZA BACILLI AS SHOWN BY CROSS AGGLUTINA- TION AND ABSORPTION TESTS
}

\author{
HoW ARD H. BELL \\ Department of Pathology, Washington University, St. Louis
}

Great endeavor has been made to throw light on the obscure problems relative to the etiology of influenza. Investigation of this character was more general during the epidemic occurring early in 1920 than during the greater one of the previous year, although the opportunity to observe patients suffering from this malady lasted over a much briefer period. In association with each epidemic much interest has been taken in the small gram-negative bacillus described by Pfeiffer ${ }^{1}$ as Bacillus influenzae. Little by little knowledge is accumulating which it is hoped will show what relation this organism may have to the disease.

In anticipation of the epidemic that occurred early in 1920, a study of the influenza bacillus was commenced late in October, 1919. A survey was made to determine the incidence of the bacillus in the upper respiratory tract of healthy medical students from different localities of the Middle West.

Great stress was laid on the technic in this survey. The swabs were prepared from fairly heavy copper wire with the terminal $15 \mathrm{~mm}$. bent to an angle of approximately 135 degrees to facilitate swabbing high in the pharynx. Cultures made from the pharynx gave more positive results than those from the tonsillar regions. The advantage gained by swabbing the pharynx had been pointed out by Winchell and Stillman. ${ }^{2}$

The medium employed was meat infusion $2 \%$ agar to which $4 \%$ defibrinated rabbit blood was added. Slightly more or less blood made no appreciable difference in the degree of growth, while marked divergence showed less favorable results. Four per cent, seemed to be the mean point of maximum growth. Brown blood was made by heating the medium to approximately $80 \mathrm{C}$. sufficiently long to pro-

Received for publication Aug 11, 1920.

1 Ztschr. f. Hyg. u. Infectionskrankh, 1893, 13, p. 357.

2 Jour. Exper. Med., 1919, 30, n. 497. 
duce a distinct brown color without a trace of red. The most desirable hydrogen-ion concentration was throught to be $P_{H} 7.3$ or 7.4. Here again organisms that grew well bore considerable variation of reaction. Nevertheless, $P_{H} 7.3$ or 7.4 represented the mean point of alkalinity showing maximum growth. It is of interest that Avery ${ }^{3}$ used a medium with a final $P_{H}$ of 7.3 to 7.5 , while Winchell and Stillman used medium with a $\mathrm{P}_{\mathrm{H}}$ of 7.2 to 7.5 . In the first part of my work red blood medium was used exclusively although later more brown blood medium was employed. Brown blood was preferred because the colonies grew more luxuriantly and were considered as characteristic to those experienced as the so-called dew-drop colonies on red blood agar.

Petri dishes were prepared and inoculated along one border from the sides of the swab by rolling it on the surface of the agar, and from this inoculated area the organisms were spread over the remaining surface of the plate with a platinum needle. The area of primary inoculation from the swab always showed a confluent growth, from which small gram-negative bacilli were demonstrated in every instance in a stained film. From 10-30 colonies were picked from the sparsely inoculated area in the endeavor to isolate the small gram-negative bacillus observed in the film. A Petri dish was divided into small squares by a glass-pencil. The colonies picked from the throat culture were inoculated into these squares and incubated 24 hours. This gave sufficient material from each colony picked to avoid losing it, and when colonies were crowded avoided contamination to a great extent. This method was fairly rapid. If the organism was not isolated from the first throat culture, subsequent cultures were made and in a few instances as many as 5 cultures were taken from the same throat. A series of 28 was studied. Failure to isolate the organism was recorded in one instance after 7 attempts, although in the stained film a few gram-negative bacilli were observed. These were accepted as influenza bacilli, if they failed to grow on meat infusion $2 \%$ agar of desirable hydrogen-ion concentration (to which $4 \%$ ascitic fluid was added) and if they grew well when $4 \%$ defibrinated blood was added.

Winchell and Stillman studied the incidence of the influenza bacillus in normal throats by reculturing once a month from December, 1918, to May, 1919, inclusive. The percentage of positive results varied from 13 to $51 \%$.

s Jour. Amer. Med. Assn., 1918, 71, p. 2050. 
Jordan ${ }^{4}$ found that 10 of 13 strains of the influenza bacillus studied by him had the property of producing indol. By plating he found the organism in $40 \%$ of normal throats. However, by testing for indol in association with mixed cultures he believes that its presence was demonstrated in $80 \%$ of his series.

The bacillus of influenza was found in the mouths of $35.1 \%$ of all healthy men examined at Camp Funston during the autumn of 1918 by Opie ${ }^{5}$ and his associates.

Lord "and his co-workers made cultures from the throats of 34 healthy Harvard students at an army training camp in order to find the bacillus of influenza and found $76 \%$ of the cultures were positive. They give a table showing the occurrence of the influenza bacillus in association with diseases other than influenza which shows that they were present in from 19 to $100 \%$ of cases in tuberculosis, measles, varicella, etc.

Park ${ }^{7}$ points out the importance of careful selection of material for culture, good medium and long training in the study of colonies. Too great emphasis cannot be laid on his comment.

It must be remembered that the survey under consideration was made on the crest of an epidemic and merged into a study of the incidence of the influenza bacillus in the throats of influenza patients.

The bacillus of influenza was isolated from the throats of all patients from whose throats I made cultures, the material being selected from patients in the St. Louis Children's Hospital. For a time the work was carried on by Dr. Park J. White, and at the beginning of his work he obtained positive cultures in about $30 \%$. This figure rose as experience and familiarity with the technic increased, until he also was able to isolate the organism from $100 \%$ of influenza patients. On recultivating the cases still accessible from which negative results had previously been obtained, he was able to isolate the organism in each instance.

$\mathrm{Opie}^{\mathrm{B}}$ and his associates, in the report on pneumonia following influenza at Camp Pike, stated that the influenza bacillus was invariably present in the upper respiratory tract of patients with influenza.

Park' ${ }^{7}$ states that Williams cultivated 278 cases for the influenza bacillus with these results:

Hospital cases $\ldots \ldots \ldots \ldots \ldots \ldots \ldots \ldots \ldots \ldots$. $80 \%$ positive

Marines ..............................

Home for Children...................... $98 \%$ positive

Pritchitt and Stillman studied the incidence of the influenza bacillus and the pneumococcus in association with influenza and pneumonia and found:

Normal $\ldots, \ldots \ldots \ldots \ldots \ldots \ldots \ldots \ldots \ldots \ldots \ldots 42 \%$ positive

Convalescent from influenza............... 46\% positive

Uncomplicated influenza $\ldots \ldots \ldots \ldots \ldots \ldots \ldots . .63 \%$ positive

Influenza with bronchopneumonia............ 93\% positive

Bronchopneumonia ......................100\% positive

Lobar pneumonia $\ldots \ldots \ldots \ldots \ldots \ldots \ldots \ldots \ldots$. 55\% positive

4 Jour. Am, Med. Assn., 1919, 72, p. 1542.

- Ibid., p. 108.

- Ibid., p. 188.

7 Ibid., 1919, 73, p. 3,18.

Ibid., 72, p. 556 .

- Jourr. Exper. Med., 1919, 29, p. 259. 
Winchell and Stillman found $39 \%$ positive in an asylum for boys in which no influenza occurred; $38 \%$ were positive among 52 convalescents from infuenza in a home for girls. Jordan ${ }^{10}$ found that $64 \%$ of cases cultivated by him between October, 1918, and February, 1919, gave positive restilts.

No attempt is made to review the literature on the incidence of the influenza bacillus in the normal throat, its incidence in association with other diseases or in association with influenza. Sufficient is quoted, however, to show the variation in results obtained.

A small diplostreptococcus resembling those studied especially by Tunnicliff $^{11}$ was observed in a number of instances. No special study was made of this organism.

The morphology of the influenza bacillus varied considerably; still it may be stated that 3 main types were observed: The more usual type was chiefly composed of small bacilli, which were fairly uniform in size and contour. $\Lambda$ few or many forms showing pleomorphism were usually present. Coccoid forms, bacilli with one end broader than the other, some large bacilli, and heavy polar staining were observed. The pleomorphism varied to some extent in degree and type, depending on the age of the culture and the medium employed. No leptothrix forms have been observed in these strains after between 4 and 6 months' cultivation on brown blood mędium. The second type was a small bacillus which was uniform in size and contour showing no pleomorphism. A subdivision of this type was made; these strains showed long slender filaments or leptothrix forms which. manifested greater or less capacity for division. The filaments were of uniform diameters. In certain instances the filaments comp'etely disappeared and only short bacilli of uniform size and contour were observed, in other instances, however, filaments recurred. The filaments at times showed unilateral or bilateral depressions on the sides, which seemed to indicate an attempt at division. A third type is represented by fairly long slender bacilli with slightly pointed ends and at times slightly curved. A few moderately long forms were seen, but as a rule the size was rather uniform. No very short forms were observed. Two strains of this type were studied and showed another peculiarity referred to later.

After long cultivation little change in the organism and cultures was observed; however, the growth was more luxuriant. Most strains produced a grayish growth on brown blood agar and the so-called "dewdrop" colonies when transferred to red blood agar. A few strains

3our. Infect. Dis., 1919,25, p. 28.

1 Ibid. 1920, 26, p. 405. 
produced a colorless growth on brown blood agar, although in several instances a slightly grayish color appeared in older cultures. All the strains required hemoglobin in the medium. No distinct and constant changes on the blood were produced by their growth. The organisms grew better aerobically and in fresh medium which was not dried.

Pfeiffer's "Bacillus influenzae" was gram-negative; the bacilli were small and forms in division resembled cocci. Long filaments were observed and considered as involution forms. The organism was nonmotile and noncapsulated. He later isolated very long forms from a child with bronchopneumonia following diphtheria, which he was unable to differentiate from the former organism and designated it as "Bacillus pseudo-influenzae."

Four years later Grassberger ${ }^{12}$ studied the morphology of this organism and recorded short forms and filamentous forms. Sometimes the poles of the bacillus showed greater affinity for stain than the body. He believed that the age of the culture and reaction of the medium influenced morphologic changes.

Wollstein ${ }^{13}$ divided her cultures into two chief types; short forms, showing pleomorphism and at times polar staining, and long forms showing a greater or less degree of division.

Galli Valerio ${ }^{14}$ discussed involution forms of this organism. $\mathrm{He}$ mentioned ovoid forms, spherical forms, clubbed forms which are often in juxtaposition, forms showing irregular staining, and long forms. These changes were observed especially in old cultures.

In 5 cases in my series colonies were picked from the same plate which fulfilled the requirements of the inftuenza bacillus, but which. however, differed in morphology. These strains were investigated by agglutination and absorption tests in 3 instances.

Twenty-seven rabbits were immunized and bled when the preliminary titration of the serum was satisfactory, that is, above 1,600 .

The strains selected were from normal throats in 5 cases and from the throats of influenza patients in 22. Nos. 2, 3, 4, 5 and 10 came from throats of students who had never had influenza. Nos. 18 and 29 were isolated from influenza suspects. The rest were isolated from typical influenza cases and as a rule early in the development of the disease, although in a few instances pneumonia was developing.

The initial dose proved fatal to several rabbits within an hour or two. Parker ${ }^{15}$ and others have demonstrated the toxicity of these organisms for laboratory animals. The most toxic strain was No. 4.

12 Ztschr, f. Hyg. u. Infektionskrankh, 1897, 25, p. 453 .

13 Jour. Exper. Med., 1915, 22, p. 445.

14 Rév. méd. de la Suisse Rom., 1919, 6, p. 265.

15 Jo11r. Immunol., 1919. 4, ค. 3.31 
This organism was isolated from a normal throat of a student who never had influenza, fully 6 weeks before the onset of the epidemic in this vicinity.

Each serum was titrated with 36 organisms in dilutions of $1: 25$, $1: 50,1: 100,1: 200,1: 400,1: 800,1: 1,600,1: 3,200$ and $1: 6,400$. In a few instances other dilutions were added. Control emulsions were always incubated. Emulsions of organisms were made by washing a 24-hour growth from the surface of a brow blood agar slant or Petri dish with salt solution. Nos. 29, 26, 31 and 32 gave difficulty. The first of these showed auto-agglutination in the control. In the remaining 3 the growth was cohesive and resisted breaking up into a fine suspension. The last two organisms are the ones described under the discussion of the morphology as type 3 . This resistance to emulsification was constant; satisfactory results were obtained by using an 18 or 24 hour-growth on several freshly prepared moist plates. This suspension was shaken for 20 minutes and centrifuged sufficiently long to throw down the larger particles, leaving the finer ones in suspension. The same technic applied to No. 29 was also satisfactory. The agglutinating tubes were incubated at $53 \mathrm{C}$. during 18 or 20 hours and read macroscopically.

It should be observed on chart 1 that cross agglutination occurred frequently in low dilutions and in a few instances in fairly high dilutions. Some serums have a wider latitude of agglutination than others. Some organisms have a greater susceptibility to agglutination than others. Perhaps this is explained by group relationship.

Absorption tests were employed in those instances which showed cross agglutination in a dilution of $1: 800$ or above. A 24-hour growth on 3 to 6 Petri dishes was washed off the agar with a dilution of $1: 25$ of the serum to be absorbed. The mixture was incubated at $53 \mathrm{C}$. for 4 hours, shaken well at 15 minute intervals, and then left to stand over night in the refrigerator. The clear serum from the top was pipeted off with a capillary pipet. The absorbed serum represented a dilution of $1: 25$. Some of the unabsorbed serum of the original dilution was kept in the incubator 4 hours at $53 \mathrm{C}$. and in the refrigerator over night; it was titrated with its own organism as a control and the result is recorded on chart 2 following the series of absorption tests for which it serves as control.

It should be observed that these organisms vary markedly in their capacity to absorb specific agglutinin from a foreign serum. 


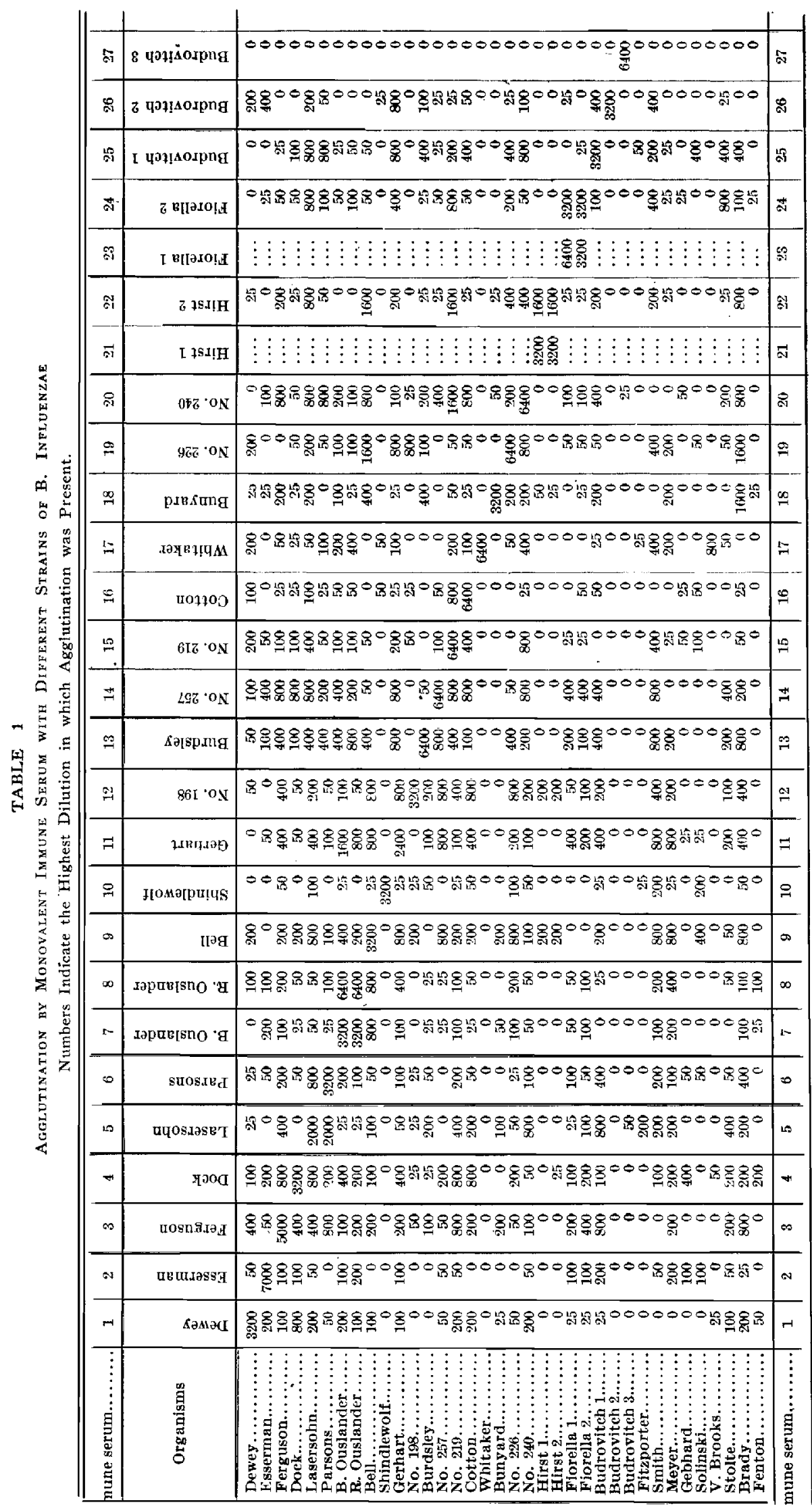


Where absorption occurred these tests were repeated two and occasionally three times to cause complete absorption if possible. The results were confirmative of the first observations. In a few instances the titer of the control was lower than the original titer of the serum. Diluted serum of several days' standing was occasionally used and the titer of this was often diminished. This made no difference, however, as the control and the absorbed serum were of the same dilution.

When a serum was absorbed by a foreign organism, this organism absorbed all, part, or none of the agglutinins for other foreign strains so tested. This was subject to considerable variation.

It should be observed that $\mathrm{B}$. Ouslander and $\mathrm{R}$. Ouslander were identical strains. These were isolated from two children of the same family suffering from influenza. Hirst 1 and Hirst 2 strains isolated from the same plate, showing marked difference in morphology, were nevertheless identical strains. Fiorella 1 and 2 were isolated from the same plate and showed a marked difference in morphology; these were identical strains. On the contrary, Budrovich 1,2 and 3, isolated from the same plate and showing marked difference in morphology, were proved to be distinct types, as shown by these tests.

The serum of No. 5, agglutinated organisms 5 and 6 in equally high dilution. By absorption tests it was shown that these organisms -were not identical. No 25 had the capacity to absorb nearly all the specific agglutinins from serum of No. 5. This test was repeated 3 times, using a greater excess of organisms, with uniform result. This relation was not reciprocal. They were not identical strains. No grouping into types can be recognized on these charts. However, certain strains are closer related than others and can be divided into subtypes to a limited extent. For example, Nos. 5 and 6 , also 9 and 19, show considerable cross agglutination. Many other strains show a close relation to these subtypes, which adds difficulty to separating them into distinct subgroups.

Two additional strains were studied later and not included in the charts. One was isolated from the lung of an adult with lobar pnetrmonia caused by the pneumococcus type 2 . The second was isolated from a child suffering from bronchopneumonia with abscess-formation following measles. Streptococcus hemolyticus and Micrococcus aureus were also isolated from the areas of consolidation. These strains resembled the organism included in the table and in no instance were they agglutinated by dilutions above $1: 800$. No absorption 
TABLE 2

Cross Aggutination After Absorption Tests

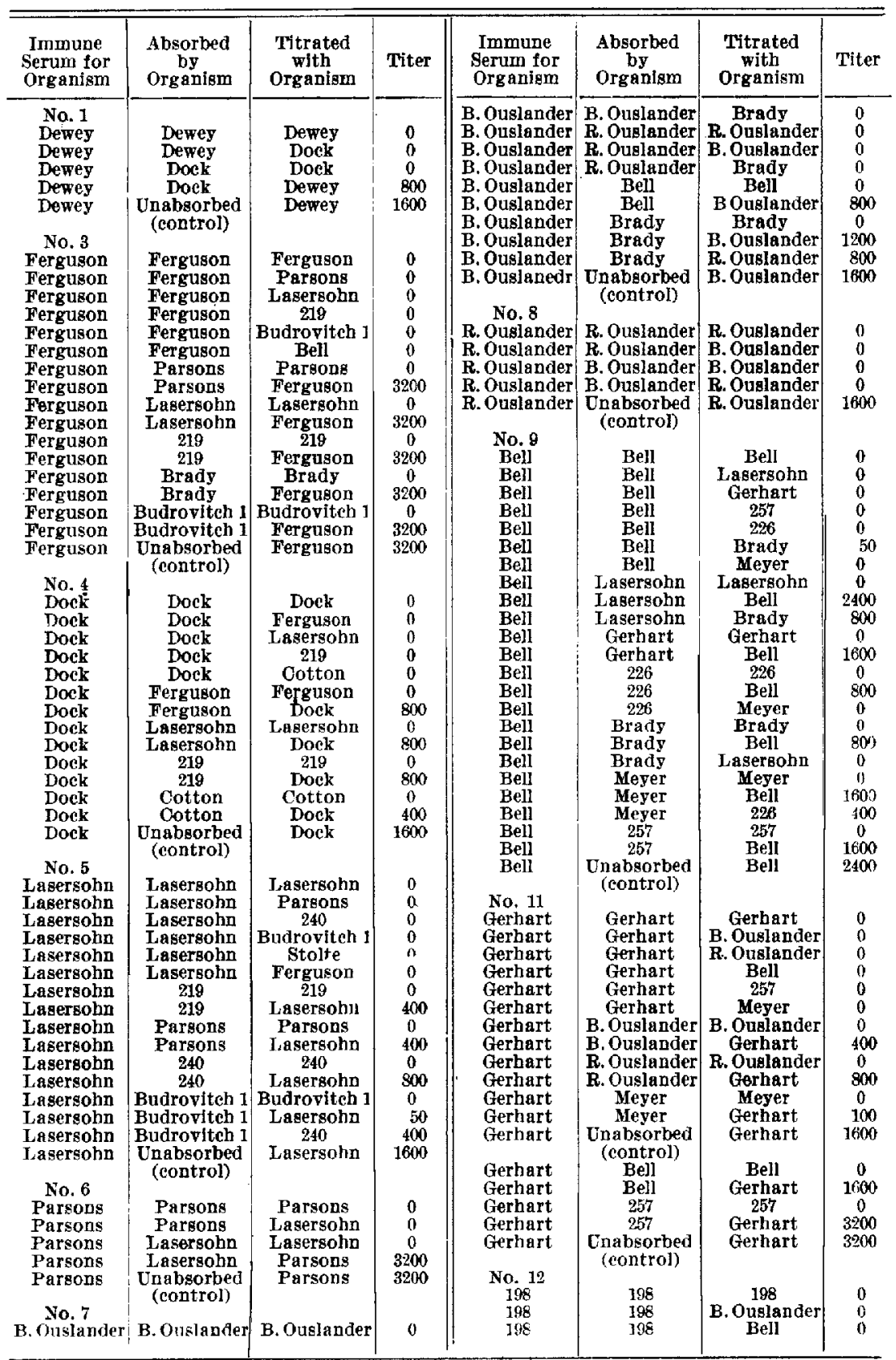


Relation of Different Strains of Influenza Bacilli

TABLE 2-Continued

Cross Agglumination After Absorption Tests

\begin{tabular}{|c|c|c|c|c|c|c|c|}
\hline $\begin{array}{l}\text { Immune } \\
\text { Serum for } \\
\text { Organism }\end{array}$ & $\begin{array}{l}\text { Absorbed } \\
\text { by } \\
\text { Organism }\end{array}$ & $\begin{array}{l}\text { Titrated } \\
\text { with } \\
\text { Organism }\end{array}$ & Titer & $\begin{array}{l}\text { Immune } \\
\text { Serum for } \\
\text { Organism }\end{array}$ & $\begin{array}{l}\text { Absorbed } \\
\text { by } \\
\text { Organism }\end{array}$ & $\begin{array}{l}\text { Titrated } \\
\text { with } \\
\text { Organlsm }\end{array}$ & Titer \\
\hline B. Ouslander & B. Ouslander & R. Ouslander & 0 & No. 16 & & & \\
\hline B. Ouelander & B. Ouslander & Bell & 0 & Cotton & Cotton & Cotton & 0 \\
\hline 198 & 198 & 257 & 0 & Cotton & Catton & 219 & 0 \\
\hline 198 & 198 & Cotton & 0 & Cotton & 210 & 219 & 0 \\
\hline 198 & 198 & Gerhart & 0 & Cotton & 219 & Ootton & 800 \\
\hline 198 & 198 & 226 & 0 & Cotton & 219 & R. Ouslander & 200 \\
\hline 188 & Bell & Bell & 0 & Cotton & Unabsorbed & Cotton & 800 \\
\hline 188 & Bell & 198 & 2400 & & (control) & & \\
\hline 198 & B. Ouslander & B. Ouslander & 0 & No. 17 & & & \\
\hline 198 & B. Onglander & 198 & 1600 & Whitaker & Whitaker & Whitaker & 0 \\
\hline 198 & Gerhart & Gerhart & 0 & Whitaker & Whitaker & V. Brooks & 0 \\
\hline 198 & Gerhart & 108 & 2400 & Whitaker & V. Brooks & V. Brooks & 0 \\
\hline 198 & 257 & 257 & 0 & Whitaker & V, Brooks & Whitaker & 3200 \\
\hline 198 & 257 & 198 & 2400 & Whitaker & Unabsorbed & Whitaker & 3200 \\
\hline 198 & Ootton & Cotton & 0 & & (control) & & \\
\hline 198 & Cotton & 198 & 1600 & No. 18 & & & \\
\hline 198 & 226 & 226 & 0 & Bunyard & Bunyard & Bunyard & 0 \\
\hline 198 & $\begin{array}{l}226 \\
\end{array}$ & 198 & 2400 & Bunyard & Bunyard & Brady & 0 \\
\hline 198 & Unabsorbed & 198 & 3200 & Bunyard & Brady & Brady & 0 \\
\hline & (control) & & & Bunyard & Brady & Bunyard & 1600 \\
\hline No. 13 & & & & Bunyard & Unabsorbed & Bunyard & 1600 \\
\hline Burdsley & Burdsley & Burdsley & 0 & & (control) & & \\
\hline Burdsley & Burdsley & Gerhart & 0 & No. 19 & & & \\
\hline Burdsley & Burdsley & 257 & 0 & 226 & 226 & 226 & 0 \\
\hline Burdsley & Burdsley & R. Ouslander & 0 & 226 & 226 & Bell & 0 \\
\hline Burdsley & Burdsley & Brady & 0 & 226 & 226 & Gerhart & 0 \\
\hline Burdsley & Gerbart & Gerhart & 0 & 226 & 226 & 198 & 0 \\
\hline Burdsley & Gerhart & Burdsley & 2400 & 226 & 226 & 240 & 0 \\
\hline Burdsley & 257 & 257 & 0 & 226 & 226 & Brady & 0 \\
\hline Burdsley & 257 & Burdsley & 2400 & $\overline{226}$ & Bell & Bell & 0 \\
\hline Burdsley & R. Ouslander & R. Ouslander & 0 & 226 & Bell & 226 & 800 \\
\hline Burdsley & R. Ouslander & Burdsley & 2400 & 226 & Gerhart & Gerhart & 0 \\
\hline Burdsley & Brady & Brady & 0 & 226 & Gerhart & 226 & 1000 \\
\hline Burdsley & Brady & Burdisley & 2400 & 226 & Gerhart & 240 & 50 \\
\hline Burdsley & Unabsorbed & Burdsley & 2400 & 296 & 198 & 198 & 0 \\
\hline No. 14 & (control) & & & $\begin{array}{l}226 \\
226\end{array}$ & 198 & $\begin{array}{c}226 \\
\text { Brady }\end{array}$ & 1600 \\
\hline $\begin{array}{c}\text { No. } 14 \\
257\end{array}$ & 257 & 257 & 0 & 226 & 240 & 240 & 0 \\
\hline 257 & 257 & Ferguson & 0 & 226 & 240 & 226 & 1600 \\
\hline 257 & 257 & Dock & 0 & 226 & 240 & Gerhart & 50 \\
\hline 257 & 257 & Lagersohn & 0 & 226 & Brady & Brady & 0 \\
\hline 257 & 257 & Gerhart & 0 & 226 & Brady & 226 & 1600 \\
\hline 257 & 257 & 219 & 0 & 226 . & Brady & 198 & 100 \\
\hline 257 & 257 & Cotton & 0 & $226^{\circ}$ & Unabsorbed & 226 & 1600 \\
\hline 257 & 257 & 240 & 0 & & (control) & & \\
\hline 257 & Ferguson & Ferguson & 0 & No. 20 & & & \\
\hline 257 & Ferguson & 357 & 3200 & 240 & 240 & 240 & 0 \\
\hline 257 & Ferguson & Dock & 200 & 240 & 240 & Ferguson & 0 \\
\hline 257 & Dock & Dock & 0 & 240 & 240 & Lasersohn & 0 \\
\hline 257 & Dock & 257 & 4800 & 240 & 240 & Parsons & 0 \\
\hline 257 & Lasersohn & Lasersohn & 0 & 240 & 240 & Bell & 0 \\
\hline 257 & Lasersohn & 257 & 4300 & 240 & 240 & Cotton & 0 \\
\hline 257 & Gerhart & Gerhart & 0 & 240 & 240 & 219 & 0 \\
\hline 257 & Gerhart & 257 & 4800 & 240 & 240 & Brady & 0 \\
\hline 257 & 219 & 219 & 0 & 340 & Ferguson & Ferguson & 0 \\
\hline 257 & 219 & 257 & 3200 & 240 & Ferguson & 240 & 3200 \\
\hline $25 \%$ & Cotton & Cotton & 0 & 240 & Lasersobn & Lasersohn & 0 \\
\hline 257 & Cotton & 257 & 4800 & 240 & Lasersohn & 240 & 800 \\
\hline 257 & 240 & 240 & 0 & 240 & Parsong & Parsons & 0 \\
\hline 257 & 240 & 257 & 4800 & 240 & Parsons & 240 & 100 \\
\hline 257 & Unabsorbed & 257 & 4800 & 240 & Bell & Bell & 0 \\
\hline & (control) & & & 240 & Bell & 240 & 1600 \\
\hline No. 15 & & & & 240 & Cotton & Cotton & 0 \\
\hline 219 & 219 & 219 & 0 & 240 & Cotton & 240 & 1600 \\
\hline 210 & 210 & 240 & 0 & 240 & 219 & 219 & 0 \\
\hline 219 & 240 & 240 & 0 & 240 & 219 & 240 & 1600 \\
\hline 219 & 240 & 219 & 3200 & 240 & Brady & Brady & 0 \\
\hline 210 & 240 & Lasergohn & 200 & 240 & Brady & 240 & 1600 \\
\hline 219 & luabsorbed & 219 & 3200 & 240 & Unabsorbed & 240 & 3200 \\
\hline & (control) & & & & & & \\
\hline
\end{tabular}


TABLE 2-Continued

Cross Agglutination After Agsorption Tests

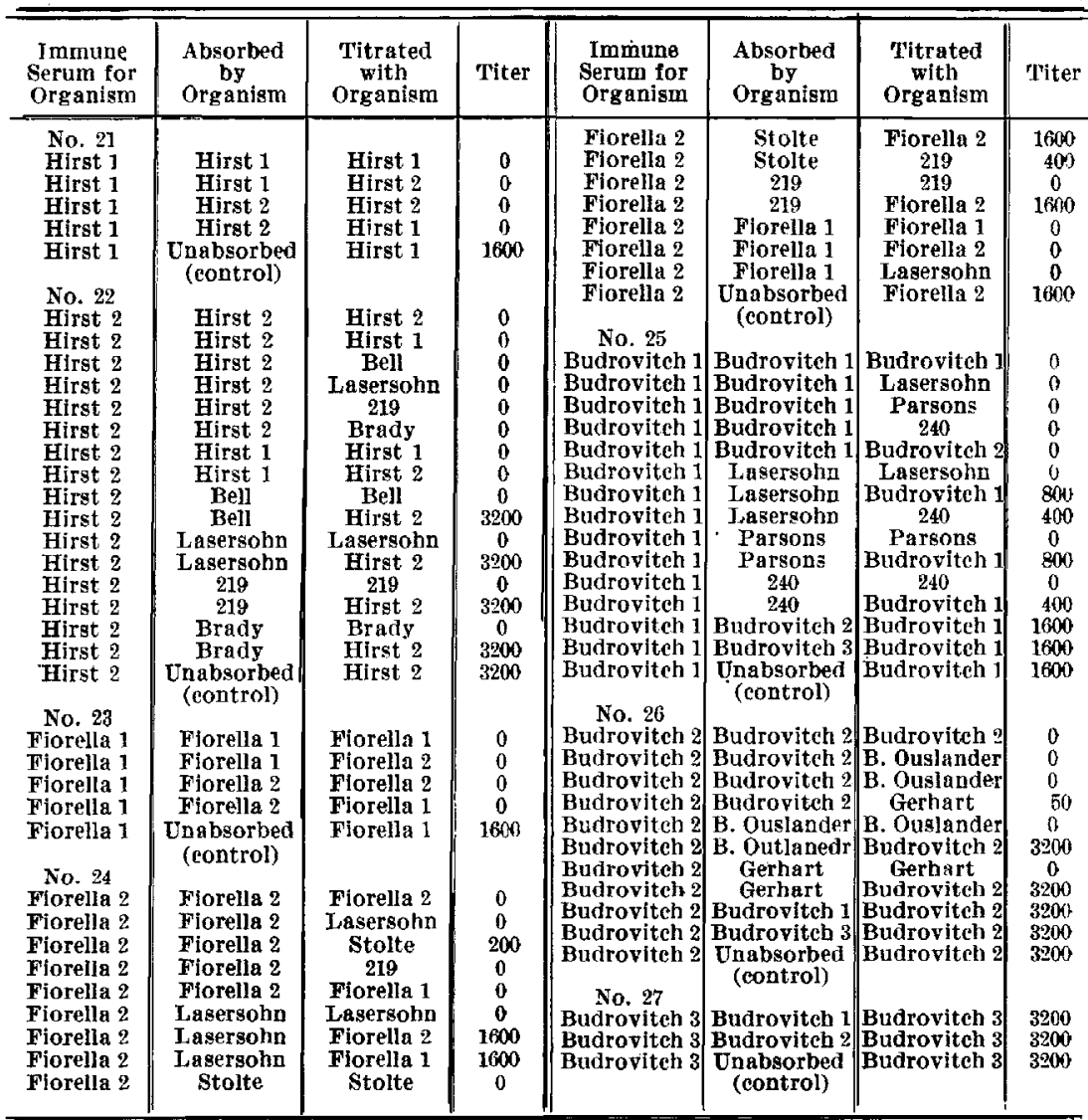

tests were made. Finally all strains were tested for agglutination with normal rabbit serum. No agglutination occurred in dilutions $1: 25$ or above.

Small and Dixon ${ }^{16}$ studied 10 strains of the influenza bacillus by agglutination and absorption tests. They concluded that this organism can be divided into groups by these methods and that they encountered 4 groups.

Park, Wollstein, and Fleming and Clemenger ${ }^{17}$ have been unable to divide the influenza bacillus into groups by agglutination. Valentine

18 Jour. Infect. Dis., 1920,26, p. 230.

17 Lancet, 1919, 2, p. 869. 
Relation of Different Strains of Influenza Bacilli 475

and Cooper, ${ }^{18}$ after employing agglutination and absorption tests, believe that they are dealing with a heterogenous group or organisms with subgroups, and that identical strains are encountered.

\section{CONCLUSIONS}

The influenza bacillus represents a heterogenous group of organisms as shown by agglutination and absorption tests. Identical strains occur.

No differentiation can be made by these methods between the organisms isolated from normal healthy throats within two months preceding the epidemic and those isolated from the throats of influenza patients.

A person may carry in the throat three different strains of this organism at the same time.

The morphology alone is unreliable as a means of dividing this group of organisms into subgroups.

18 Jour. of Immunol., 1919, 4, p. 359. 